\title{
Subsonic Flutter of Cantilever Rectangular PC Plate Structure
}

\author{
Kemal Yaman \\ The Scientific and Technical Research Council of Turkey, Defense Industries Research and Development Institute (TÜBİTAK-SAGE), \\ Mamak, 06261 Ankara, Turkey \\ Correspondence should be addressed to Kemal Yaman; kemal.yaman@tubitak.gov.tr
}

Received 20 January 2016; Accepted 23 May 2016

Academic Editor: Hamid M. Lankarani

Copyright ( 2016 Kemal Yaman. This is an open access article distributed under the Creative Commons Attribution License, which permits unrestricted use, distribution, and reproduction in any medium, provided the original work is properly cited.

Flutter characteristics of cantilever rectangular flexible plate structure under incompressible flow regime are investigated by comparing the results of commercial flutter analysis program $\mathrm{ZAERO}^{\odot}$ with wind tunnel tests conducted in Ankara Wind Tunnel (ART). A rectangular polycarbonate (PC) plate, $5 \times 125 \times 1000 \mathrm{~mm}$ in dimension, is used for both numerical and experimental investigations. Analysis and test results are very compatible with each other. A comparison between two different solution methods $\left(g\right.$-method and $k$-method) of ZAERO ${ }^{\odot}$ is also done. It is seen that the $k$-method gives a closer result than the other one. However, $g$-method results are on a conservative side and it is better to use conservative results, namely, $g$-method results. Even if the modal analysis results are used for the flutter analysis for this simple structure, a modal test should be conducted in order to validate the modal analysis results to have accurate flutter analysis results for more complicated structures.

\section{Introduction}

Interaction of aerodynamic, inertial, and elastic forces may result in instabilities. One of the most important instabilities known in aeroelasticity is flutter. Flutter is an aeroelastic instability which involves one flapwise and one torsional degrees of freedom (DoF). Coupling of the torsional structural mode with the flapwise bending mode results in a flutter mode. Torsion of the structure is the result of the aerodynamic forces. The angle of attack is changed by the torsion. As a result of angle of attack change, the aerodynamic lift force is also changed [1].

The change of angle of attack due to torsion changes the lift in an unfavorable phase with the flapwise bending which results in flutter. Vibrations grow rapidly at flutter speed. Structural damping cannot compensate the negative damping caused by the flutter mode. Flutter is observed above a certain relative wind speed on the structure; this speed is called the critical flutter speed [2]. Design of a new air vehicle or a new external store for an existing air vehicle is a complicated design task. That design task gets more complicated since more complex systems are desired by the consumers as a result of rapid progress in the engineering technology. It is also expected to decrease the design cost of these new products since the cost is always an important design consideration. Another important design consideration is the time. There is no infinite time for research and development of a new product. MIL-HDBK-1763 "Aircraft/Stores Compatibility: Systems Engineering Data Requirements and Test Procedures" explains how to certify a newly developed military aircraft or a new external store for an existing combat aircraft. Some of the tests designated in this standard are expensive and time-consuming, like ground vibration testing (GVT) and flutter test. Therefore, it is expected to decrease time and expenses consumed for these tests. The main objective of this work is to determine degree of accuracy of flutter analysis results of plate-like structures in incompressible flow compared to wind tunnel flutter test results and also compare the $k$-method and $g$-method solution methods of $\mathrm{ZAERO}^{\odot}$. It is also objected to compare the different modal analysis results, in which different structural boundary conditions are used, with the modal test result of the plate-like structure. More accurate flutter analyses are going to decrease the number of flutter tests.

In this study, flutter analyses were realized with $\mathrm{ZAERO}^{\odot}$, commercial aeroelastic analysis software that uses panel method based on linearized potential flow theory. Modal parameters (natural frequencies and mode shapes) required 
by ZAERO $^{\odot}$ were obtained from MSC NASTRAN $^{\odot}$ solver. All structural FE models were constructed in MSC PATRAN $^{\odot}$. Finally, all flutter tests were conducted in Ankara Wind Tunnel (ART).

The study of flutter begins with the research of Lanchester [3] and Bairstow and Fage [4] in 1916 about the antisymmetrical flutter of a Handley Page bomber. In 1918, Blasius [5] started to make some calculations for the Albatros D3 biplane due to the failure of the lower wing of that plane. The development of the flutter analysis is increased after the development of nonstationary airfoil theory by Kutta and Joukowsky.

The torsion flutter was first found by Glauret in 1929. It is discussed in detail by Smilg [6]. Several types of single degree of freedom flutter involving control surfaces at both subsonic and supersonic speeds have been found $[7,8]$. Pure bending flutter of a cantilever swept wing occurs if the wing is heavier than the surrounding air and has a sufficiently large sweep angle [9]. The bending torsion in an incompressible fluid has been studied by Greidanus [10]. Dugundji [11] searched for panel flutter and the rate of damping.

Dowell $[12,13]$ investigated the two- and three-dimensional plate undergoing cyclic oscillations and aeroelastic instability. Cantilever beam with tip loads having an arbitrary cross section is discussed by Kosmatka [14] using a power series solution technique for the out-of-plane flexure and torsion case. Subsonic flight and supersonic flight are an ordinary event nowadays. Hypersonic flights become more and more popular due to increased needs. As a result, aeroelastic analyses become a more important part of the design of a new aircraft or an external store for an existing aircraft.

Libo et al. [15] designed a wind tunnel test model for the flutter analysis. The model was used in a complete flutter certification procedure. GVT, model updating, and flutter analysis were all done for this model. $P-k$ solution method was used in flutter analysis.

Neal et al. [16] worked on the design and wind tunnel analysis of a fully adaptive aircraft configuration. The goal of the study was to determine the effect of the sweep, span extension, and tail extension on the aerodynamic characteristics of the model.

Omar and Kurban [17] designed a free-wing unmanned aerial vehicle model and tested it in low speed closed circuit wind tunnel to see the effect of the angle of attack and Reynold's number.

Samikkannu [18] studied the details of fabrication and ground and wind tunnel testing of a scaled aeroelastic model of T-Tail with a flexible fuselage. Composite materials were used to obtain the required dynamics for the model during the GVT. Wind tunnel test was done in order to see the flutter characteristics of the model.

Strand and Levinsky [19] conducted wind tunnel tests for a free-wing tilt-propeller V/STOL airplane model in order to see aerodynamic characteristics of the model airplane. Lift and drag curves of the airplane have been obtained as a function of propeller tilt angle and thrust coefficient.

In this study, ZAERO ${ }^{\odot}$, flutter analysis software based on linearized potential flow theory and developed by $\mathrm{ZONA}^{\odot}$
Inc., is used for aeroelastic stability analysis. At this point, it is necessary to explain the aeroelastic theory behind the software. Here, some theoretical background is given. In the Nomenclature, the symbols used in equations and corresponding meanings are tabulated.

\section{Methods}

2.1. Aeroelastic Stability Equations. The equation of motion of an aeroelastic system can be stated as follows [20]:

$$
\left[M_{G G}\right]\{\ddot{x}(t)\}+\left[K_{G G}\right]\{x(t)\}=\{F(t)\} .
$$

$\{F(t)\}$ consists of two parts:

$$
\{F(t)\}=\left\{F_{a}(t)\right\}+\left\{F_{e}(t)\right\} .
$$

Combining (1) and (2) gives

$$
\left[M_{\mathrm{GG}}\right]\{\ddot{x}(t)\}+\left[K_{\mathrm{GG}}\right]\{x(t)\}-\left\{F_{a}(t)\right\}=\left\{F_{e}(t)\right\} .
$$

If $\left\{F_{a}(t)\right\}$ is nonlinear with respect to $\{x(t)\}$, flutter analysis is performed by a time-marching procedure solving the following equation:

$$
\left[M_{G G}\right]\{\ddot{x}(t)\}+\left[K_{G G}\right]\{x(t)\}-\left\{F_{a}(t)\right\}=0
$$

with initial conditions $x(0)$ and $\dot{x}(0)$.

Amplitude linearization assumption converts (4) into an eigenvalue problem for flutter analysis. In this case, the aerodynamic feedback $\left\{F_{a}(t)\right\}$ is related to the structural deformation $\{x(t)\}$ by means of the following convolution integral:

$$
\left\{F_{a}(x)\right\}=\int_{0}^{t} q_{\infty}\left[H\left(\frac{V}{L}(t-\tau)\right)\right]\{x(\tau)\} \mathrm{d} \tau
$$

where $[H((V / L)(t-\tau))]$ represents the aerodynamic transfer function and $L$ is defined as: $L=c / 2$.

The Laplace domain counterpart of (5) is simply

$$
\left\{F_{a}(x(s))\right\}=q_{\infty}\left[\bar{H}\left(\frac{s L}{V}\right)\right]\{x(s)\} .
$$

Equation (4) now can readily be transformed into the Laplace domain and results in an eigenvalue problem in terms of $s$ given as follows:

$$
\left[s^{2}\left[M_{G G}\right]+\left[K_{G G}\right]-q_{\infty}\left[\bar{H}\left(\frac{s L}{V}\right)\right]\right]\{x(s)\}=\{0\} .
$$

2.1.1. Modal Reduction Approach. Solving (7) directly is computationally costly since the FE model of an aircraft contains higher DoF. Therefore, the mass and stiffness matrices are very large in size. Modal reduction approach is used to solve this problem. Structural deformation is expressed in terms of modal coordinates as follows:

$$
\{x(s)\}=[\Phi]\{q(s)\} .
$$


Substituting (8) into (7) and premultiplying (7) with $[\Phi]^{T}$ yield the following flutter equation:

$$
\begin{aligned}
& {\left[s^{2}[\Phi]^{T}\left[M_{G G}\right][\Phi]+[\Phi]^{T}\left[K_{G G}\right][\Phi]\right.} \\
& \left.\quad-q_{\infty}[\Phi]^{T}\left[\bar{H}\left(\frac{s L}{V}\right)\right][\Phi]\right]\{q(s)\}=\{0\} .
\end{aligned}
$$

Equation (9) can be written as follows:

$$
\begin{aligned}
& {\left[s^{2}\left[M_{H H}\right]+\left[K_{H H}\right]-q_{\infty}\left[Q_{h h}\left(\frac{s L}{V}\right)\right]\right]\{q(s)\}} \\
& =\{0\},
\end{aligned}
$$

where $\left[M_{H H}\right]=[\Phi]^{T}\left[M_{G G}\right][\Phi],[K]=[\Phi]^{T}\left[K_{G G}\right][\Phi]$, and $\left[Q_{h h}(s L / V)\right]=[\Phi]^{T}[\bar{H}(s L / V)][\Phi]$ is the generalized aerodynamic force matrix.

The modal reduction approach provided reduces the size of the eigenvalue problem. Solving this equation is easier than solving (7). Equation (10) is the classical flutter matrix equation.

In order to achieve that conversion, it is desired to obtain aerodynamic transfer function.

ZAERO $^{\odot}$ obtains unsteady aerodynamics methods in the frequency domain by assuming simple harmonic motion. The obtained aerodynamic transfer function is called the Aerodynamic Influence Coefficient (AIC) matrix.

2.1.2. Unified AIC of ZAERO ${ }^{\odot}$. ZONA6 and ZONA7 are unsteady aerodynamics methods incorporated in ZAERO ${ }^{\odot}$. ZONA6 generates AIC matrices for subsonic flow regimes, and ZONA7 generates AIC matrices for supersonic flow regimes. One of the fundamental aerodynamic parameters is the reduced frequency and it is defined as

$$
k=\frac{\omega L}{V} .
$$

ZAERO $^{\odot}$ uses the panel method which is based on the linearized potential flow theory to solve the integral equations.

\subsubsection{Flutter Solution Techniques}

(1) $k$-Method. The classical flutter matrix equation derived in Section 2.1.1 is given as

$$
\left[s^{2}\left[M_{h h}\right]+\left[K_{h h}\right]-q_{\infty}\left[Q_{h h}\left(\frac{s L}{V}\right)\right]\right]\{q(s)\}=\{0\} .
$$

Unsteady aerodynamics methods are used by $\mathrm{ZAERO}^{\odot}$ to formulate aerodynamic transfer function in frequency domain ( $k$-domain):

$$
[\bar{H}(i k)]=[G]^{T}[\operatorname{AIC}(i k)][G] .
$$

The frequency domain counterpart of the classical flutter matrix equation can be obtained as follows:

$$
\left[-\omega^{2}\left[M_{h h}\right]+\left[K_{h h}\right]-q_{\infty}\left[Q_{h h}(i k)\right]\right]\{q\}=\{0\} .
$$

If we add artificial structural damping to (14), the $k$-method flutter equation is obtained as follows:

$$
\begin{aligned}
& {\left[-\omega^{2}\left[M_{h h}\right]+\left(1+i g_{s}\right)\left[K_{h h}\right]-q_{\infty}\left[Q_{h h}(i k)\right]\right]\left\{q_{i k}\right\}} \\
& \quad=\{0\} .
\end{aligned}
$$

$g_{s}$ is the added artificial structural damping.

(2) $g$-Method. Assume an analytic function in the form of $\left[Q_{h h}(p)\right]=\left[Q_{h h}(g+i k)\right]$ in the domain of $g \geq 0$ and $g<0 .\left[Q_{h h}(p)\right]$ can be expanded along the imaginary axis (i.e., $g=0$ ) for small $g$ by means of damping perturbation method:

$$
\left[Q_{h h}(p)\right] \approx\left[Q_{h h}(i k)\right]+\left.g \frac{\partial\left[Q_{h h}(p)\right]}{\partial g}\right|_{g=0}
$$

for $g \ll 1$.

If $\left[Q_{h h}(p)\right]$ is analytic, it must satisfy the Cauchy-Riemann equations such that

$$
\begin{gathered}
\frac{\partial\left[\operatorname{Re}\left(Q_{h h}(p)\right)\right]}{\partial g}=\frac{\partial\left[\operatorname{Im}\left(Q_{h h}(p)\right)\right]}{\partial k}, \\
\frac{\partial\left[\operatorname{Im}\left(Q_{h h}(p)\right)\right]}{\partial g}=-\frac{\partial\left[\operatorname{Re}\left(Q_{h h}(p)\right)\right]}{\partial k} .
\end{gathered}
$$

Combining (17) and (18) yields the following general equation:

$$
\frac{\partial\left[\left(Q_{h h}(p)\right)\right]}{\partial g}=\frac{\partial\left[\left(Q_{h h}(p)\right)\right]}{\partial(i k)} .
$$

Thus, the term $\left.\left(\partial\left[Q_{h h}(p)\right] / \partial g\right)\right|_{g=0}$ can be replaced by

$$
\begin{aligned}
\left.\frac{\partial\left[Q_{h h}(p)\right]}{\partial g}\right|_{g=0} & =\left.\frac{\partial\left[Q_{h h}(p)\right]}{\partial(i k)}\right|_{g=0}=\frac{d Q_{h h}(i k)}{d(i k)} \\
& =\left[Q_{h h}^{\prime}(i k)\right] .
\end{aligned}
$$

Substituting (19) into (20) yields the approximated $p$-domain solution of $\left[Q_{h h}(p)\right]$ in terms of $k$ for small $g$ :

$$
\left[Q_{h h}(p)\right] \approx\left[Q_{h h}(i k)\right]+g\left[Q_{h h}^{\prime}(i k)\right] .
$$

Substituting (21) into (12) yields the $g$-method equation as follows:

$$
\begin{aligned}
& {\left[\frac{V^{2}}{L^{2}}\left[M_{h h}\right] p^{2}+\left[K_{h h}\right]-q_{\infty}\left[Q_{h h}^{\prime}(i k)\right] g\right.} \\
& \left.-q_{\infty}\left[Q_{h h}(i k)\right]\right]\{q\}=\{0\} .
\end{aligned}
$$

2.2. Flutter Certification Procedures. Aircraft are flown to their maximum speeds to show that they are structurally safe at those speeds. After the investigation of the flutter phenomena, flutter tests became an important part of the design 


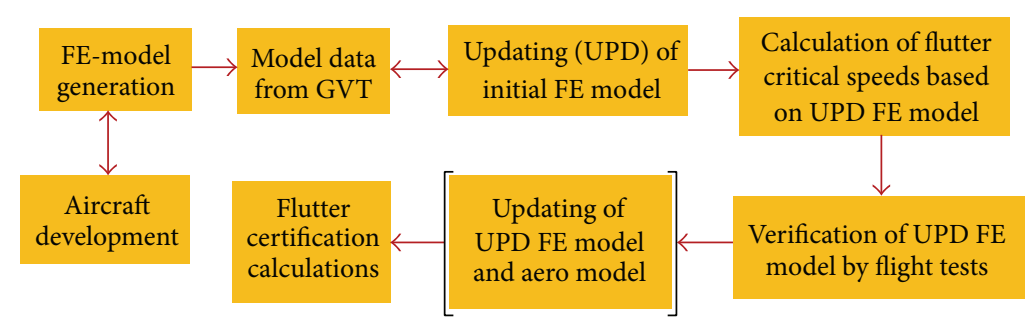

FIGURE 1: Actual verification and validation process of aeroelastic aircraft models [21].

and modification of the air vehicles. Figure 1 emphasizes the verification and validation steps for an aeroelastic aircraft model.

As it can be seen in that figure, flutter certification is a very complicated task. Every step of this certification procedure requires a large amount of work power, time, and money. Flutter certification procedure can be summarized in five steps sequentially as follows:

(1) Determination of the test configurations.

(2) Ground vibration testing (GVT).

(3) FE-model updating.

(4) Aeroelastic flutter analysis.

(5) Flight flutter tests.

2.2.1. Test Configurations. Passenger planes are designed and they are used. Therefore, their flutter certification is done once. However, fighter aircraft are designed and they are capable of carrying different types and numbers of external stores. Those external stores are not used arbitrarily. They are used in a concept of operation for the aircraft. The concept of operation defines the types and number of munitions that the combat aircraft carries and the location of the munitions on the aircraft stores.

All different external store configurations have their own structural and aerodynamic identity. For each of those configurations, it is necessary to rearrange the flutter certification procedure. Determination of the test configurations is very critical since it is the starting point of the flutter test procedure.

2.2.2. Ground Vibration Testing (GVT). After the test configurations are determined, GVT for each configuration is conducted. GVT is necessary to validate and update the mathematical model of the aircraft by using experimentally determined low-frequency modes of the whole aircraft structure. This mathematical model of the aircraft is used in flutter analysis for reliable flutter estimations.

2.2.3. FE-Model Updating. The results of the GVT are used for FE-model updating. Validated FE model is used to predict the critical flutter speeds of the aircraft, and then it is necessary to progress carefully in the model updating stage. Due to this reason, the model updating procedure takes up to several weeks. Another reason for model updating to be done as accurately as possible is that the usage of the updated
FE model for the flutter calculations enables covering future modifications on the aircraft without any additional GVT. FE model can be updated for smaller modifications on the structure and it can be used for the flutter calculations of the modified aircraft.

2.2.4. Flutter Analysis. Updated FE model is used in aeroelastic analysis in order to obtain information about the flutter behavior of the aircraft. Computer programs specialized for the flutter analysis, for example, $\mathrm{ZAERO}^{\odot}$, or some finite element analysis programs such as NASTRAN ${ }^{\odot}$ can be used for flutter analysis. These results determine the safety limit for the flight flutter tests.

2.2.5. Flight Flutter Test. Flutter flight tests are the final step of the flutter certification procedure of the aircraft. As a result of the aeroelastic analyses, most critical configurations in terms of flutter are determined. Flight flutter tests are conducted for those critical configurations. As a result of flight flutter test, flight envelope of the aircraft after the modification is determined. Structural excitation during the flutter test is necessary to detect the impending aeroelastic instabilities. For aircrafts, up to $60 \mathrm{~Hz}$ excitation is necessary to excite the selected vibration modes. Lower excitation results in lower aerodynamic damping values than the actual damping levels and large scatter in damping values from the response data. Excitation system should be light enough not to change the modal characteristics of the aircraft.

The most effective way to obtain the desired excitation is to use inertia shakers. Aerodynamic force is also a simple way to obtain the excitation force. In that type of excitation, aerodynamic vanes have a small airfoil mounted at the tip of the wing or stabilizer. Atmospheric turbulence is also used for the excitation during the flight flutter tests [22]. It is necessary to have an excitation point far away from a nodal line [23]. Response of the aircraft to excitation should also be recorded. Then, instrumentation is another important factor in flight flutter testing.

Accelerometer is used in order to obtain the response of the aircraft during the flight flutter test. The location and the number of measurement points should be chosen carefully in order to get good enough data from the measurements. Pulse code modulation (PCM) or digital telemetry is used in order to transfer the measured responses from the aircraft to the ground station [24]. A typical characteristic of a good measurement point is that data obtained from that point should reflect the mode shapes of the aircraft [24]. After 


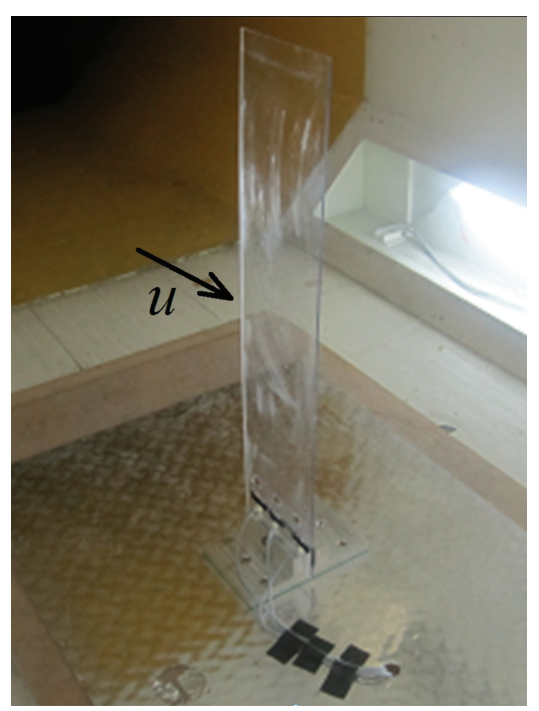

(a)

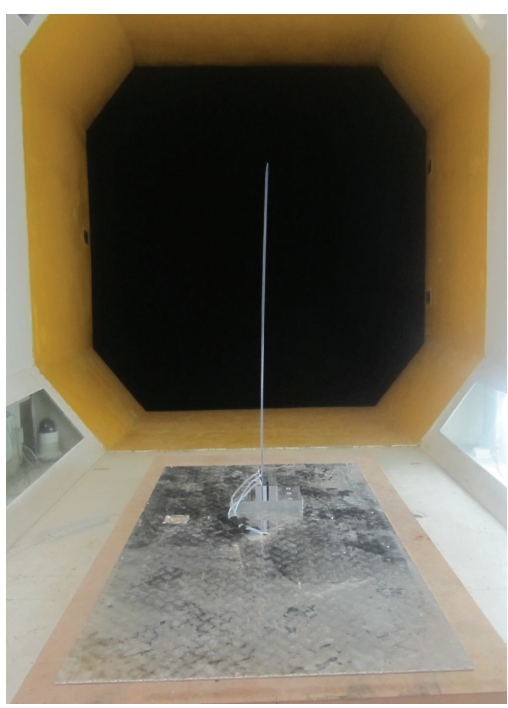

(b)

FIGURE 2: Experimental setup for PC plate structure: (a) side view and (b) front view.

the response data is obtained, it is necessary to analyze it for flutter occurrence. Some of the methods used for flutter prediction are extrapolating damping trends, discrete time autoregressive moving average model, and the flutterometer.

\section{Experimental Study}

Within the scope of this study, plate-like structure is analyzed and tested for flutter. In the wind tunnel tests, the rectangular polycarbonate $(\mathrm{PC})$ plate with the dimension of $5 \times 125 \times$ $1000 \mathrm{~mm}$ is used. In Figure 2, the experimental setups are given for polycarbonate (PC) rectangular plate structure. The $\mathrm{PC}$ plate is placed parallel to the flow.

Wind tunnel tests are conducted at Ankara Wind Tunnel (ART). ART is a subsonic wind tunnel which has a maximum speed of $90 \mathrm{~m} / \mathrm{s}$. Firstly, wind tunnel test of the rectangular plate is conducted. Plate is fixed to the floor of the wind tunnel with a fixture as shown in Figure 2. Strain gauges are used to obtain strain data and they are positioned at the root of the plate.

\section{Numerical Modeling and Analysis}

Material properties of PC obtained from the literature and used in FE model of the plate structures are given in Table 1.

Modal analyses of the plate structures have been carried out by MSC NASTRAN ${ }^{\odot}$. FE models were constructed for 1/10 scaled cantilever beam plate. Fixed boundary condition and modal parameters of the FE model that correlate best with modal test data were used in flutter analyses.

4.1. Aeroelastic Model. Aeroelastic model of the rectangular plate obtained with $\mathrm{ZAERO}^{\odot}$ is shown in Figure 3. Half of the system is modeled in order to simplify the model and shorten
TABLE 1: Material properties of $(5 \times 125 \times 1000 \mathrm{~mm})$ PC used in FE model.

\begin{tabular}{lc}
\hline Property & Value \\
\hline Elastic modulus $(\mathrm{GPa})$ & 3.5 \\
Poisson ratio & 0.35 \\
Density $\left(\mathrm{kg} / \mathrm{mm}^{3}\right)$ & $1.2 e-6$ \\
Mass $(\mathrm{kg})$ & 0.75 \\
$I x$ & 62502 \\
$I y$ & 63476 \\
$I z\left(\mathrm{~kg} \mathrm{~mm}^{2}\right)$ & 978 \\
$E I 1$ & $4.6 e 6$ \\
$E I 2$ & $2.8 e 9$ \\
$G J\left(\mathrm{~N} \mathrm{~mm}^{2}\right)$ & $6.6 e 6$ \\
\hline
\end{tabular}

the analysis time. The body is modeled as a cylinder and the tip of the body is sharpened in order not to affect the flow around the rectangular plate during flutter analysis.

Aeroelastic model of the rectangular plate has 40 elements in spanwise direction and 5 elements in chordwise direction. The body in the aeroelastic model has $125 \mathrm{~mm}$ diameter in its cylindrical section.

\section{Results and Discussion}

Experimental and numerical results and comparison of them are given under this topic.

5.1. Wind Tunnel Test Results. Firstly, wind tunnel test of the rectangular plate is conducted. Plate is fixed to the floor of the wind tunnel with a fixture as shown in Figure 2. Strain gauges are used to obtain strain data and they are positioned at the root of the plate as shown in Figure 4. The strain data 


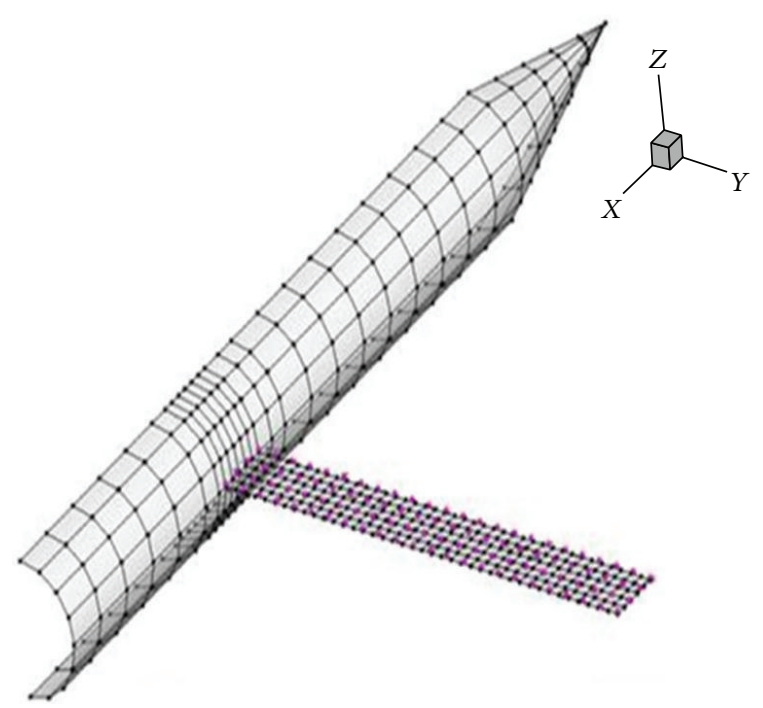

FIGURE 3: Aeroelastic model of the rectangular plate.

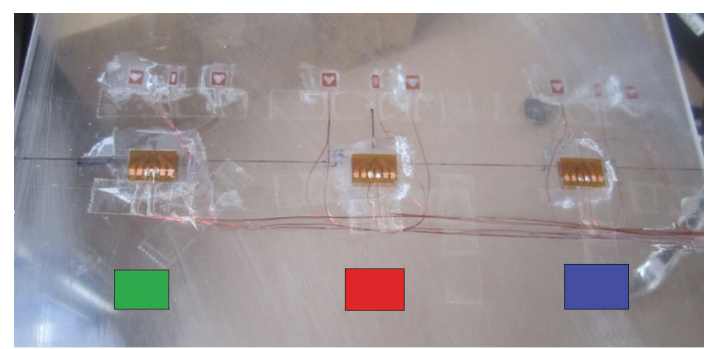

FIGURE 4: Strain gauge placement for the rectangular plate test.

and the PSD of blue gauge obtained from the strain gauges during the wind tunnel test are given in Figures 5(a) and 5(b), respectively.

As it can be seen in strain-time data, during the flutter occurrence, strain values change in an uncontrolled manner. After flutter observation in test, the wind tunnel is stopped and the strain data goes back to its normal progress.

Three different (green, red, and blue) strain gauges are attached to the same horizontal line (Figure 4). During the flutter occurrence, the responses of the green, red, and blue gauges are given in the same graph. Wind tunnel speed was $24.89(\mathrm{~m} / \mathrm{s})$ and frequency was $8.9(\mathrm{~Hz})$ when the flutter is observed at the rectangular plate as indicated in Table 2.

5.2. FEM Analysis Results. Modal analyses of the plate structures have been carried out by MSC NASTRAN ${ }^{\odot}$. It is seen in Figure 6 that the first four modes are first bending at $1.08 \mathrm{~Hz}$, second bending at $6.75 \mathrm{~Hz}$, first torsion at $14.89 \mathrm{~Hz}$, and third bending at $18.90 \mathrm{~Hz}$ in sequence for the rectangular plate. The first 10 natural frequencies are also given in Table 3.

The first four mode shapes are shown in Figures 6(a), 6(b), 6(c), and 6(d).

5.3. Flutter Analysis Results. Results of the flutter analysis for the rectangular plate indicate a flutter speed between $22.5 \mathrm{~m} / \mathrm{s}$
TABLE 2: Wind tunnel flutter test results for the rectangular plate.

\begin{tabular}{llcc}
\hline Test \# & Test configuration & $\begin{array}{c}\text { Flutter speed } \\
(\mathrm{m} / \mathrm{s})\end{array}$ & $\begin{array}{c}\text { Flutter frequency } \\
(\mathrm{Hz})\end{array}$ \\
\hline 1 & Rectangular plate & 24.89 & 8.9 \\
\hline
\end{tabular}

TABLE 3: The first 10 natural frequencies of the rectangular plate.

\begin{tabular}{lccccccccc}
\hline Mode number & 1 & 2 & 3 & 4 & 5 & 6 & 7 & 8 & 9 \\
\hline Freq. (Hz) & 1.1 & 6.8 & 14.9 & 18.9 & 26.5 & 37 & 44.9 & 61.4 & 91.9 \\
\hline
\end{tabular}

and $23.9 \mathrm{~m} / \mathrm{s}$ and a flutter frequency between $10.4 \mathrm{~Hz}$ and $9.7 \mathrm{~Hz}$ for the assumed structural damping between $0 \%$ and $4 \%$ at the third mode as shown in Table 4 . Figure 7 shows the damping-speed graph $(V-g$ plot $)$ and Figure 8 shows the frequency-speed graph ( $V-f$ plot) of the rectangular plate for the first four modes.

In $V-g$ plot, when damping of one of the modes goes from negative side to positive side, it is said that speed is the flutter speed for the structure. Table 4 indicates flutter onset at $22.5 \mathrm{~m} / \mathrm{s}$ for this case. It is also obtained that the third mode causes the flutter for the rectangular plate.

5.3.1. Comparison of $k$-Method and g-Method Results. When the results for the rectangular plate are investigated, it is seen that both of the results are in good agreement with the test result. But $k$-method solution result is better than the $g$ method. Since there is not much nonlinearity in test setup for this case, the results are close to each other. The general comparison between the test result and the flutter analysis is given in Figures 9 and 10.

\section{Conclusion}

Tables 5 and 6 show the comparison of the $g$-method and $k$ method flutter analysis results with the wind tunnel flutter test results. It is obvious that flutter speed estimation of ZAERO ${ }^{\odot}$ for this case is in great agreement with the wind tunnel test results for both solution methods.

ZAERO $^{\odot}$ estimates lower flutter speed than the wind tunnel test results. Therefore, it can be said that analysis results are conservative. It is also concluded that results for the $k$-method solution are better when compared to $g$-method.

Flutter frequency estimation is better in $k$-method solution when compared to the $g$-method. Some reasons for the so exact flutter speed estimation can be given as the system is highly linear and flutter is easily observed for this large plate in wind tunnel test. As a result of this study, it is concluded that it is sufficient to use modal analysis results in flutter analysis for simple structures.

As shown in Tables 5 and 6, without using GVT and structural model updating, for a simple plate structure, the difference between flutter speed estimated by the analysis software and flutter test result is below $10 \%$ which is quite acceptable. Of course, in case of more complicated structures, GVT and model updating are a must for reliable and accurate aeroelastic analysis. $\mathrm{ZAERO}^{\odot} k$-method solution is found to 
TABLE 4: Flutter speed analysis results of the rectangular plate.

\begin{tabular}{lccccccccc}
\hline Structural damping, G & $0.0 \%$ & $0.5 \%$ & $1.0 \%$ & $1.5 \%$ & $2.0 \%$ & $2.5 \%$ & $3.0 \%$ & $3.5 \%$ & $4.0 \%$ \\
\hline Speed $(\mathrm{m} / \mathrm{s})(\mathrm{g}$-method) & 22.5 & 22.6 & 22.8 & 23.0 & 23.2 & 23.3 & 23.5 & 23.7 & 23.9 \\
Frequency $(\mathrm{Hz})$ (g-method) & 10.4 & 10.3 & 10.2 & 10.2 & 10.1 & 10.0 & 9.9 & 9.8 & 9.7 \\
Speed $(\mathrm{m} / \mathrm{s})($-method) & 23.8 & 24.0 & 24.2 & 24.4 & 24.6 & 24.8 & 25.0 & 25.2 & 25.4 \\
Frequency $(\mathrm{Hz})(k$-method) & 9.7 & 9.6 & 9.5 & 9.4 & 9.3 & 9.2 & 9.1 & 9.0 & 8.9 \\
\hline
\end{tabular}

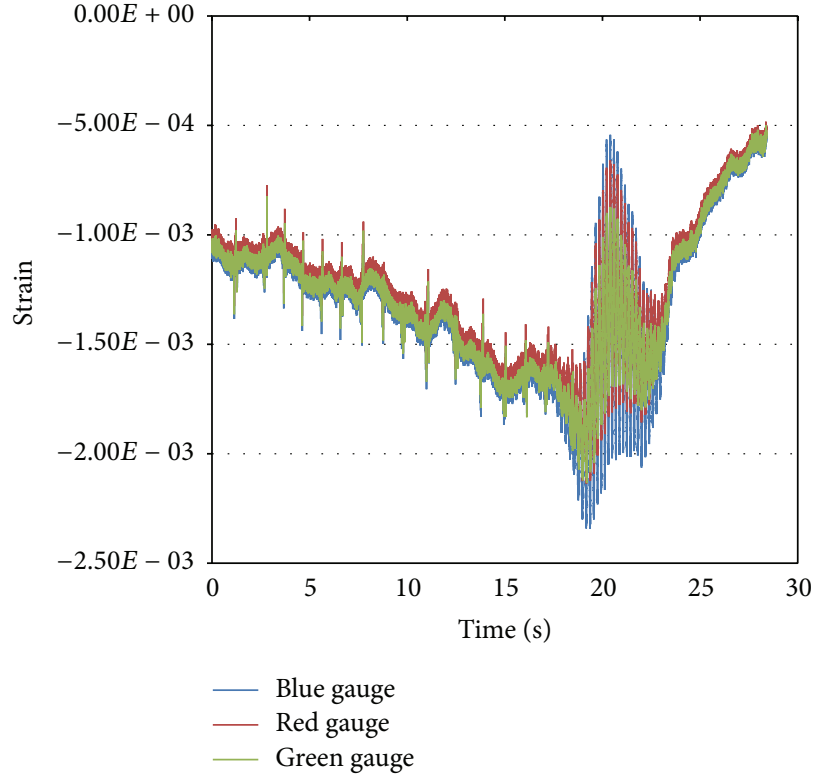

(a)

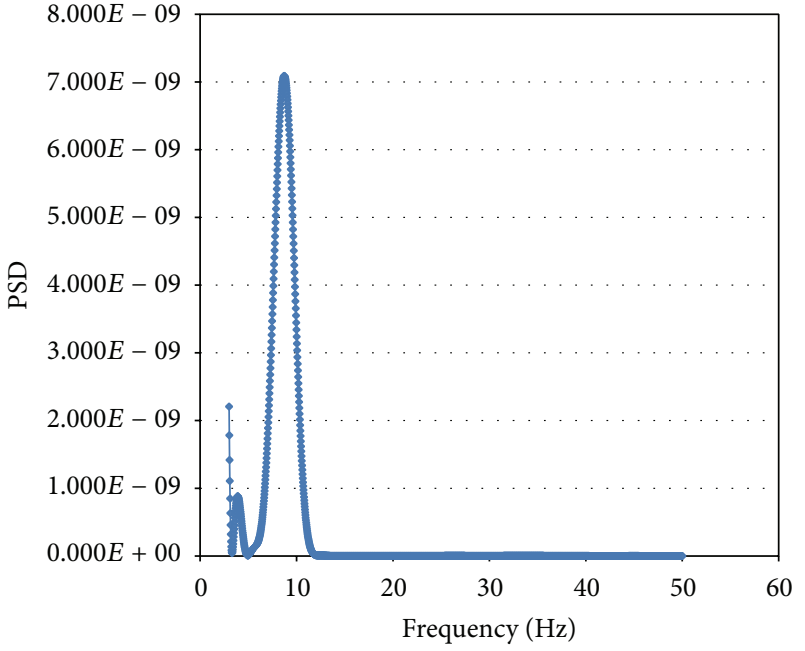

(b)

FIgURE 5: (a) Strain-time and (b) PSD graph of the rectangular plate test item during the wind tunnel test.

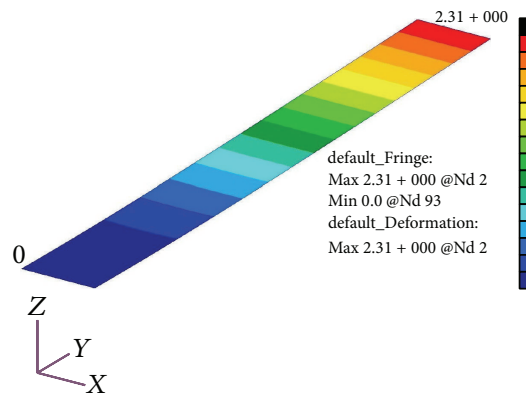

(a)

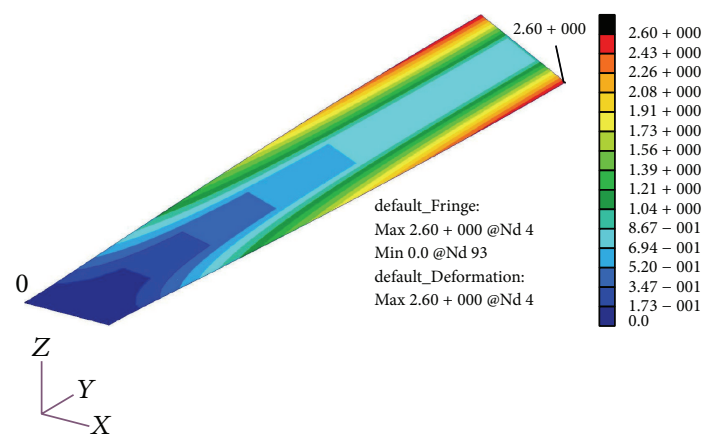

(c)

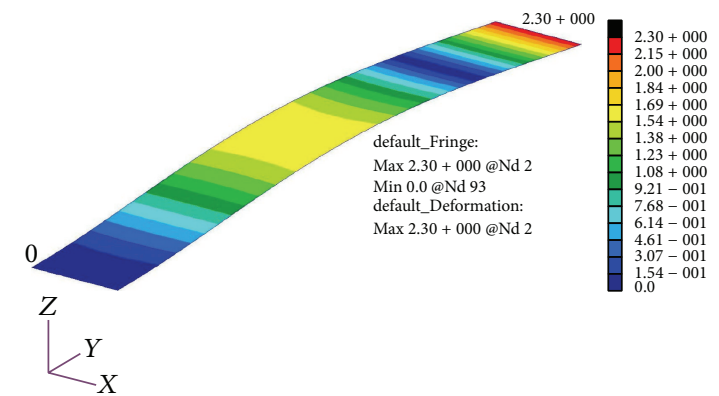

(b)

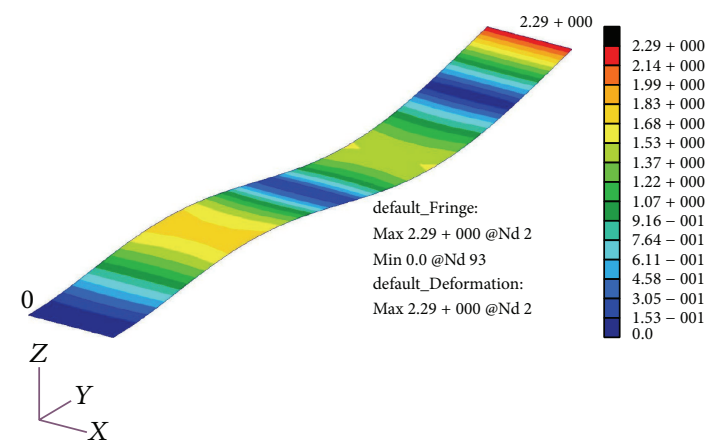

(d)

Figure 6: First four (a, b, c, d) modes of the rectangular plate. 
TABLE 5: Comparison of wind tunnel flutter test with flutter analysis for the rectangular plate for $g$-method.

\begin{tabular}{|c|c|c|c|c|c|c|}
\hline \multicolumn{3}{|c|}{ ZAERO $^{\odot}(g-$ method $)$} & \multicolumn{2}{|c|}{ Test } & \multirow{2}{*}{$\begin{array}{l}\text { Speed change } \\
(\mathrm{m} / \mathrm{s})\end{array}$} & \multirow{2}{*}{$\begin{array}{c}\text { Freq. change } \\
(\mathrm{Hz})\end{array}$} \\
\hline $\begin{array}{l}\text { Assumed struc. } \\
\text { damping (\%) }\end{array}$ & Flutter speed $(\mathrm{m} / \mathrm{s})$ & Flutter freq. (Hz) & Flutter speed $(\mathrm{m} / \mathrm{s})$ & Flutter freq. (Hz) & & \\
\hline 0 & 22.5 & 10.4 & 24.9 & 8.8 & 9.6 & 18.2 \\
\hline 0.5 & 22.6 & 10.3 & 24.9 & 8.8 & 9.2 & 17.0 \\
\hline 1.0 & 22.8 & 10.2 & 24.9 & 8.8 & 8.4 & 15.9 \\
\hline 1.5 & 23.0 & 10.2 & 24.9 & 8.8 & 7.6 & 15.9 \\
\hline 2 & 23.2 & 10.1 & 24.9 & 8.8 & 6.8 & 14.7 \\
\hline 2.5 & 23.3 & 10.0 & 24.9 & 8.8 & 6.4 & 13.6 \\
\hline 3 & 23.5 & 9.9 & 24.9 & 8.8 & 5.6 & 12.5 \\
\hline 3.5 & 23.7 & 9.8 & 24.9 & 8.8 & 4.8 & 11.4 \\
\hline 4 & 23.9 & 9.7 & 24.9 & 8.8 & 4.0 & 10.2 \\
\hline
\end{tabular}

TABLE 6: Comparison of wind tunnel flutter test with flutter analysis for the rectangular plate for $k$-method.

\begin{tabular}{|c|c|c|c|c|c|c|}
\hline \multirow{2}{*}{$\begin{array}{l}\text { Assumed struc. } \\
\text { damping (\%) }\end{array}$} & \multicolumn{2}{|l|}{ ZAERO $^{\odot}(k$-method $)$} & \multicolumn{2}{|c|}{ Test } & \multirow{2}{*}{$\begin{array}{l}\text { Speed change } \\
(\mathrm{m} / \mathrm{s})\end{array}$} & \multirow{2}{*}{$\begin{array}{c}\text { Freq. change } \\
(\mathrm{Hz})\end{array}$} \\
\hline & Flutter speed $(\mathrm{m} / \mathrm{s})$ & Flutter freq. (Hz) & Flutter speed $(\mathrm{m} / \mathrm{s})$ & Flutter freq. $(\mathrm{Hz})$ & & \\
\hline 0 & 23.8 & 9.7 & 24.9 & 8.8 & 4.4 & 10.2 \\
\hline 0.5 & 24.0 & 9.6 & 24.9 & 8.8 & 3.6 & 9.1 \\
\hline 1.0 & 24.2 & 9.5 & 24.9 & 8.8 & 2.8 & 8.0 \\
\hline 1.5 & 24.4 & 9.4 & 24.9 & 8.8 & 2.0 & 6.8 \\
\hline 2 & 24.6 & 9.3 & 24.9 & 8.8 & 1.2 & 5.7 \\
\hline 2.5 & 24.8 & 9.2 & 24.9 & 8.8 & 0.4 & 4.5 \\
\hline 3 & 25.0 & 9.1 & 24.9 & 8.8 & 0.4 & 3.4 \\
\hline 3.5 & 25.2 & 9.0 & 24.9 & 8.8 & 1.2 & 2.3 \\
\hline 4 & 25.4 & 8.9 & 24.9 & 8.8 & 2.0 & 1.1 \\
\hline
\end{tabular}

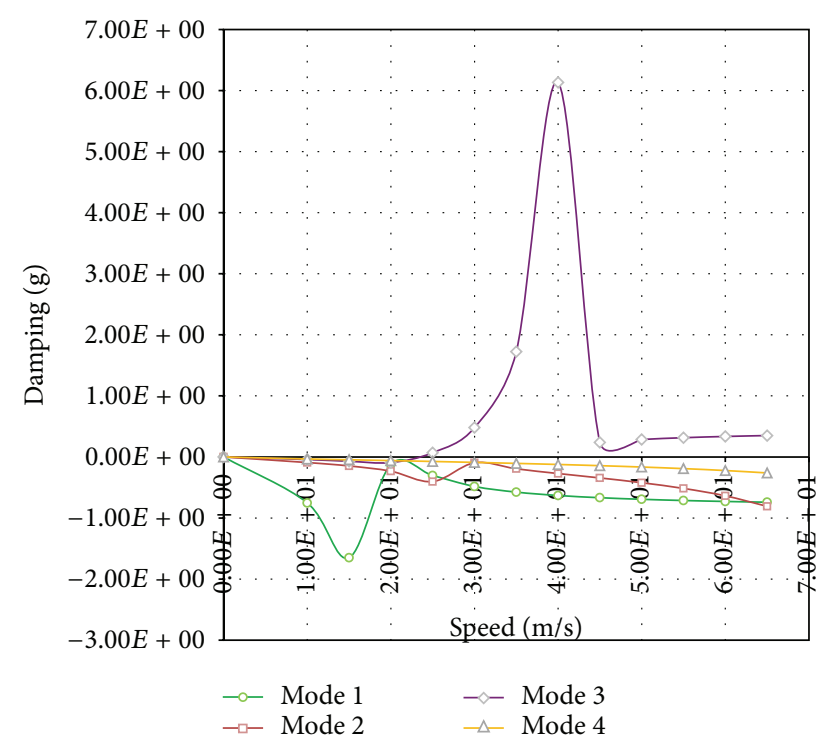

FIGURE 7: $V-g$ plot of the rectangular plate.

be more accurate than the $g$-method solution. However, $g$ method results are on the conservative side which is very critical in flutter tests since flutter tests are conducted for

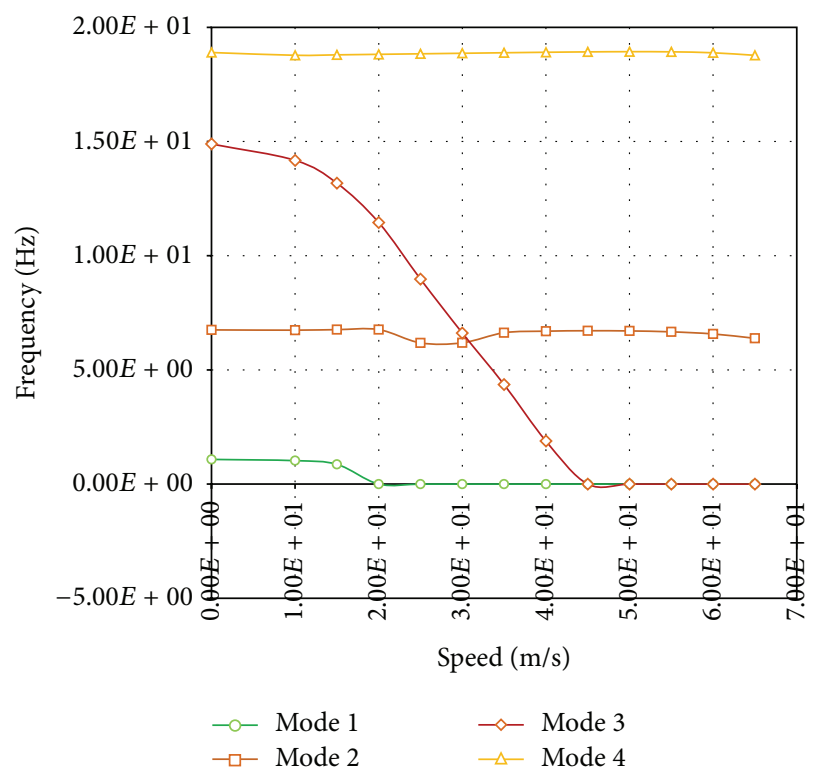

FIGURE 8: $V-f$ plot of the rectangular plate.

critical conditions of the fighter aircraft. Then, it is better to use $g$-method results for the flutter analysis. 


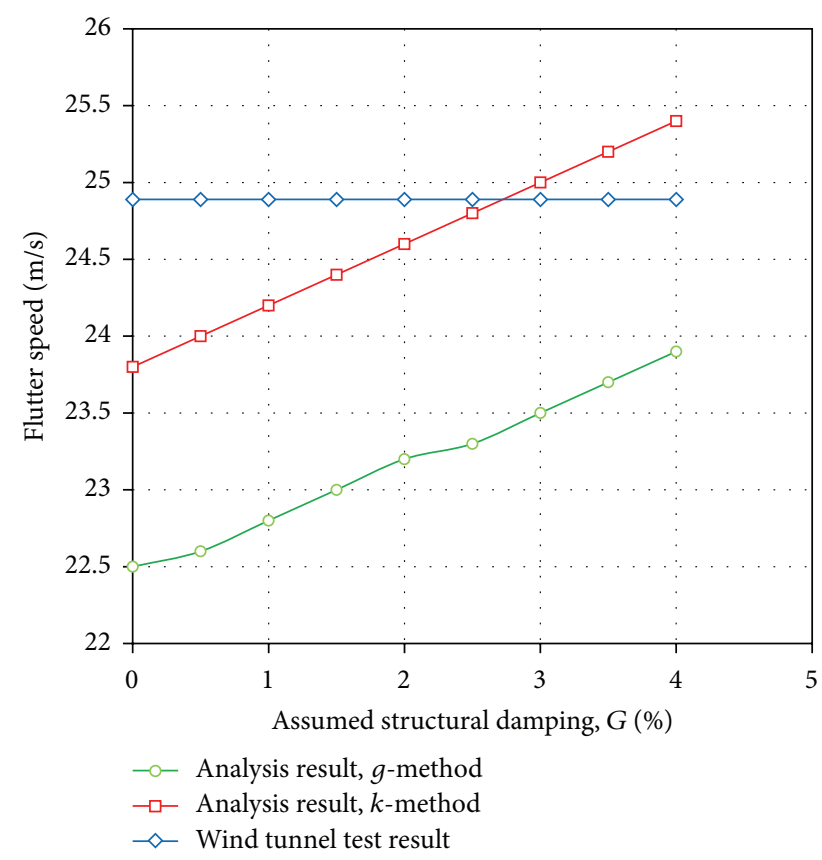

FIGURE 9: Flutter speed comparison between test and analysis result versus assumed structural damping.

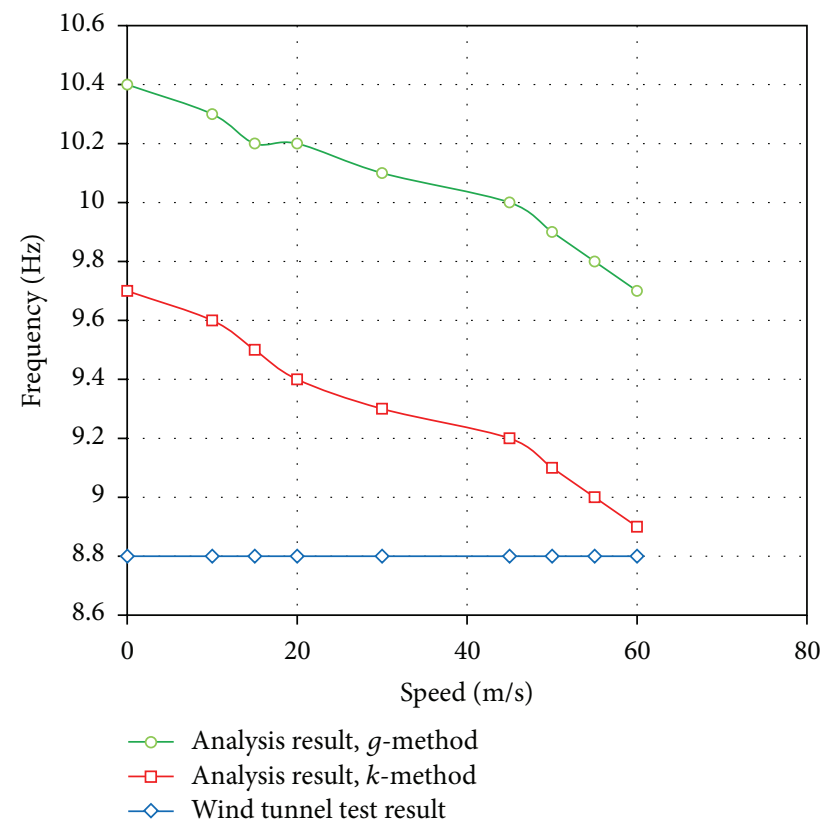

FIGURE 10: Flutter frequency comparison between test and analysis result versus speed.

\section{Nomenclature}

$\left[M_{G G}\right]$ : Generalized mass matrix generated by structural FE model

$\left[K_{G G}\right]$ : Generalized stiffness matrix generated by structural FE model

$\{x(t)\}$ : Structural deformation $\{\ddot{x}(t)\}: \quad$ Second derivative of the structural deformation

$\{F(t)\}$ : Aerodynamic forces applied on the structure

$\left\{F_{a}(t)\right\}$ : Aerodynamic forces induced by the structural deformation

$\left\{F_{e}(t)\right\}$ : External forces

$q_{\infty}$ : Aerodynamic pressure

$L: \quad$ Reference length

$c: \quad$ Reference chord length

$V: \quad$ Velocity of the undisturbed flow

$[\Phi]: \quad$ Truncated modal matrix

$\{q(s)\}:$ Generalized coordinates, that is, modal coordinates

$\left[M_{H H}\right]$ : Generalized (modal) mass matrix

$[K]: \quad$ Generalized (modal) stiffness matrix

$\omega: \quad$ Harmonic oscillatory frequency

$\{h\}: \quad$ Structural deformation defined at the aerodynamic boxes

$\left\{F_{h}\right\}: \quad$ Resultant aerodynamic forces at the aerodynamic boxes due to $\{h\}$

$\{\delta h\}: \quad$ Virtual displacement

$\{\delta x\}: \quad$ Virtual displacement

$\gamma: \quad$ Transient decay rate coefficient.

\section{Competing Interests}

The author declares that there are no competing interests regarding the publication of this paper.

\section{Acknowledgments}

The author wishes to thank TÜBİTAK-SAGE for their motivations, supports of equipment, and workforce in order to carry out this study.

\section{References}

[1] M. H. Hansen, "Aeroelastic instability problems for wind turbines," Wind Energy, vol. 10, no. 6, pp. 551-577, 2007.

[2] Y. C. Fung, An Introduction to the Theory of Aeroelasticity, Courier Dover Publications, Mineola, NY, USA, 2002.

[3] F. W. Lanchester, "Torsional vibration of the Tail of an Aeroplane," Aeronaut. Research Com. R \& M.276, part i, 1916.

[4] L. Bairstow and A. Fage, "Oscillations of the tail plane and body of an aeroplane in flight," Aeronaut. Research Com. R \& M.276, part ii, 1916.

[5] H. Blasius, "Über schwingungserscheinungen an einholmigen unterflügeln," Zeitschrift für Fugtechnik und Motorluftschiffahrt, vol. 16, pp. 39-42, 1925.

[6] B. Smilg, "The instability of pitching oscillations of an airfoil in subsonic incompressible potential flow," Journal of the Aeronautical Sciences, vol. 16, no. 11, pp. 691-696, 1949.

[7] H. Cheilik and H. Frissel, "Theoretical criteria for single degree of freedom flutter at supersonic speeds," Cornell Aeronautical Laboratory Report CAL-7A, 1947.

[8] H. L. Runyan, H. J. Cunningham, and C. E. Watkins, “Theoretical investigation of several types of single-degree-of-freedom 
flutter," Journal of the Aeronautical Sciences, vol. 19, no. 2, pp. 101-110, 1952.

[9] H. J. Cunningham, "Analysis of pure-bending flutter of a cantilever swept wing and its relation to bending-torsion flutter," NACA Technical Note, 1951.

[10] J. H. Greidanus, "Low-speed flutter," Journal of the Atmospheric Sciences, vol. 16, pp. 127-128, 1949.

[11] J. Dugundji, "Theoretical considerations of panel flutter at high supersonic Mach numbers," AIAA Journal, vol. 4, no. 7, pp. 12571266, 1966.

[12] E. H. Dowell, "Nonlinear oscillation of a fluttering plate," AIAA Journal, vol. 4, no. 7, pp. 1267-1265, 1966.

[13] E. H. Dowell and H. M. Voss, "Theoretical and experimental panel flutter studies in the Mach number range 1.0 to 5.0," AIAA Journal, vol. 3, no. 12, pp. 2292-2304, 1965.

[14] J. B. Kosmatka, "Flexure-torsion behavior of prismatic beams," AIAA Journal, vol. 31, no. 1, pp. 170-179, 1993.

[15] W. Libo, S. Long, C. Lei, W. Zhigang, and Y. Chao, "Design and analysis of a wind tunnel test model system for gust alleviation of aeroelastic aircraft," in Proceedings of the 53rd AIAA/ASME/ASCE/AHS/ASC Structures, Structural Dynamics and Materials Conference, pp. 23-26, Honolulu, Hawaii, USA, April 2012.

[16] D. A. Neal, M. G. Good, C. O. Johnson, H. H. Robertshaw, W. H. Mason, and D. J. Inman, "Design and wind-tunnel analysis of a fully adaptive aircraft configuration," in Proceedings of the 45th AIAA/ASME/ASCE/AHS/ASC Structures, Structural Dynamics \& Materials Conference, AIAA 2004-1727, pp. 19-22, Palm Springs, Calif, USA, April 2004.

[17] A. A. Omar and A. Kurban, "Design, fabrication and experimental testing of IIUM free wing unmanned aerial vehicle (IIUM-FWUAV)," Australian Journal of Basic and Applied Sciences, vol. 5, no. 6, pp. 381-389, 2011.

[18] R. Samikkannu, "Wind tunnel flutter testing of composite T-tail model of a transport aircraft with fuselage flexibility," in Wind Tunnels and Experimental Fluid Dynamics Research, J. C. Lerner, Ed., In Tech, Rijeka, Croatia, 2011.

[19] T. Strand and E. S. Levinsky, "Wind tunnel tests of a free-wing tilt-propeller V/Stol Airplane Model," Aeronautical Research Report, 1969.

[20] ZAERO Theoretical Manual, Version 8.5, ZONA 02-12.4, 2011.

[21] G. Gloth, M. Degener, U. Füllekrug et al., "New ground vibration testing techniques for large aircraft," Sound and Vibration, vol. 35, no. 11, pp. 14-18, 2001.

[22] D. Göge, M. Böswald, U. Füllekrug, and P. Lubrina, "Ground vibration testing of large aircraft-State-of-the-art and future perspectives," in Proceedings of the 25th Conference and Exposition on Structural Dynamics (IMAC '07), Orlando, Fla, USA, February 2007.

[23] M. W. Kehoe, "A historical overview of flight flutter testing," NASA Technical Memorandum 4720, NASA, Washington, DC, USA, 1995.

[24] D. J. Ewins, Modal Testing: Theory, Practice and Application, Research Studies Press, Baldock, UK, 2000. 


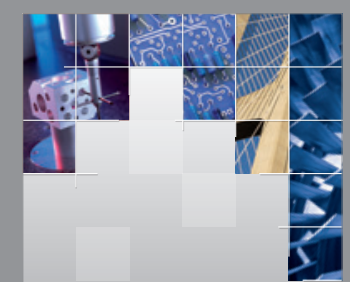

\section{Enfincering}
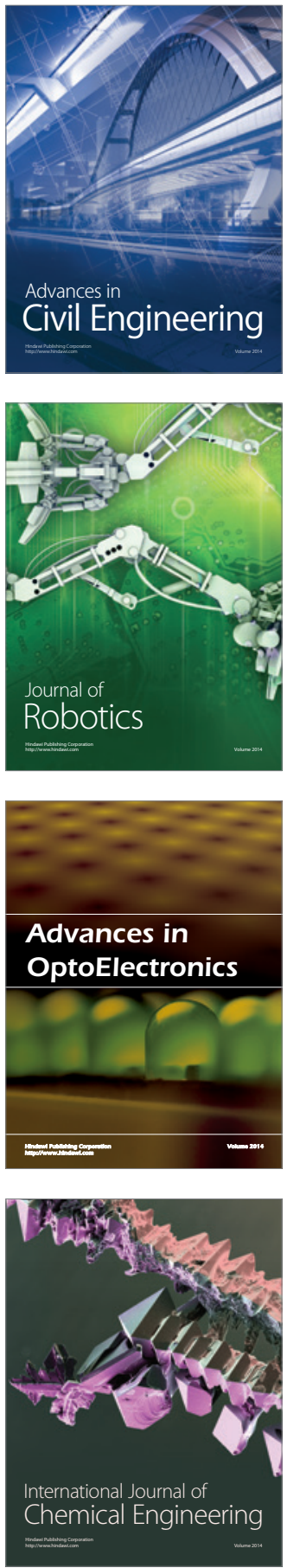

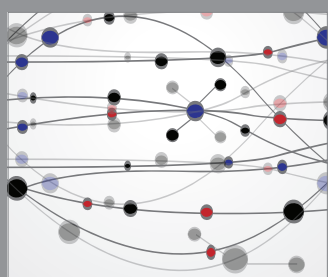

The Scientific World Journal

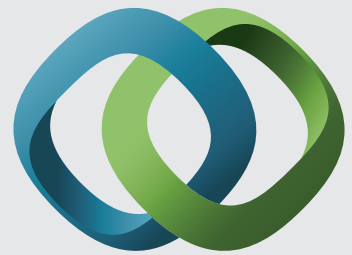

\section{Hindawi}

Submit your manuscripts at

http://www.hindawi.com
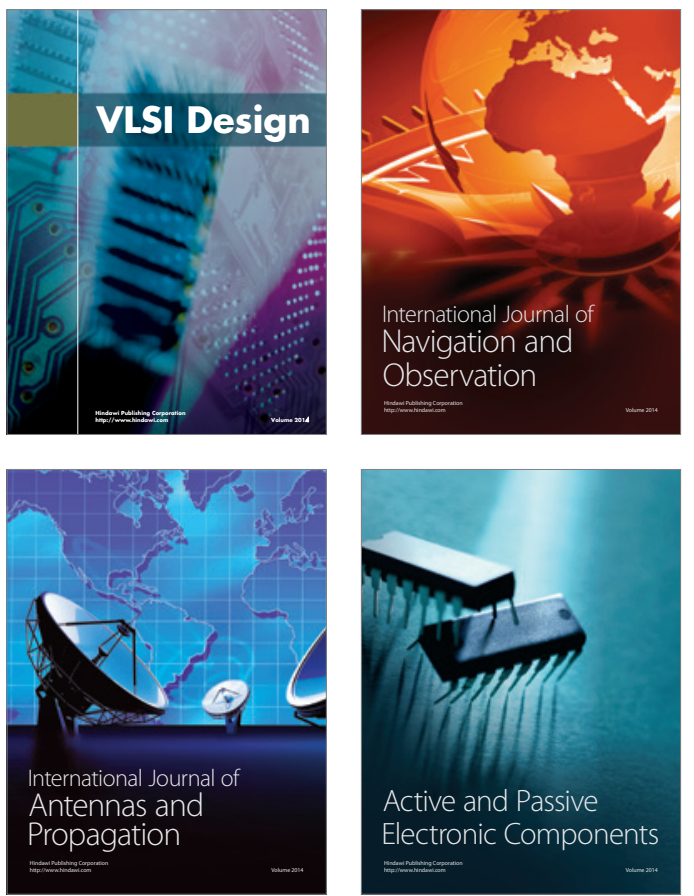
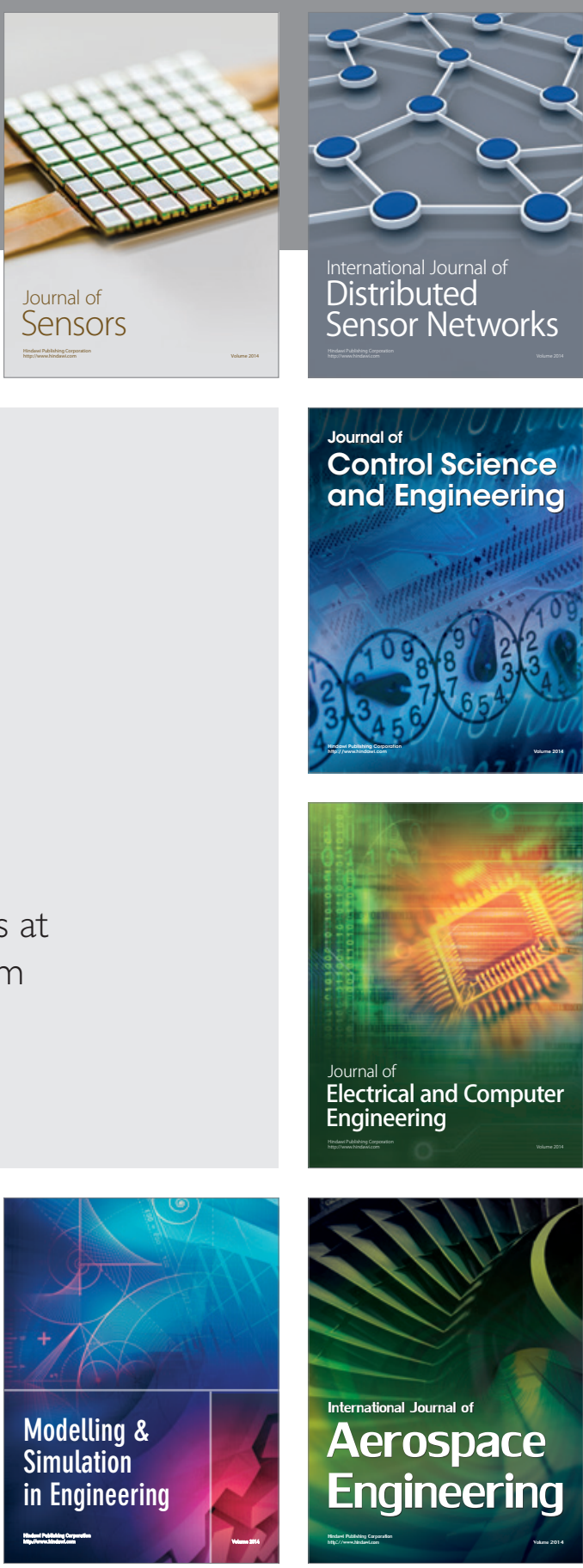

International Journal of

Distributed

Sensor Networks

Journal of

Control Science

and Engineering
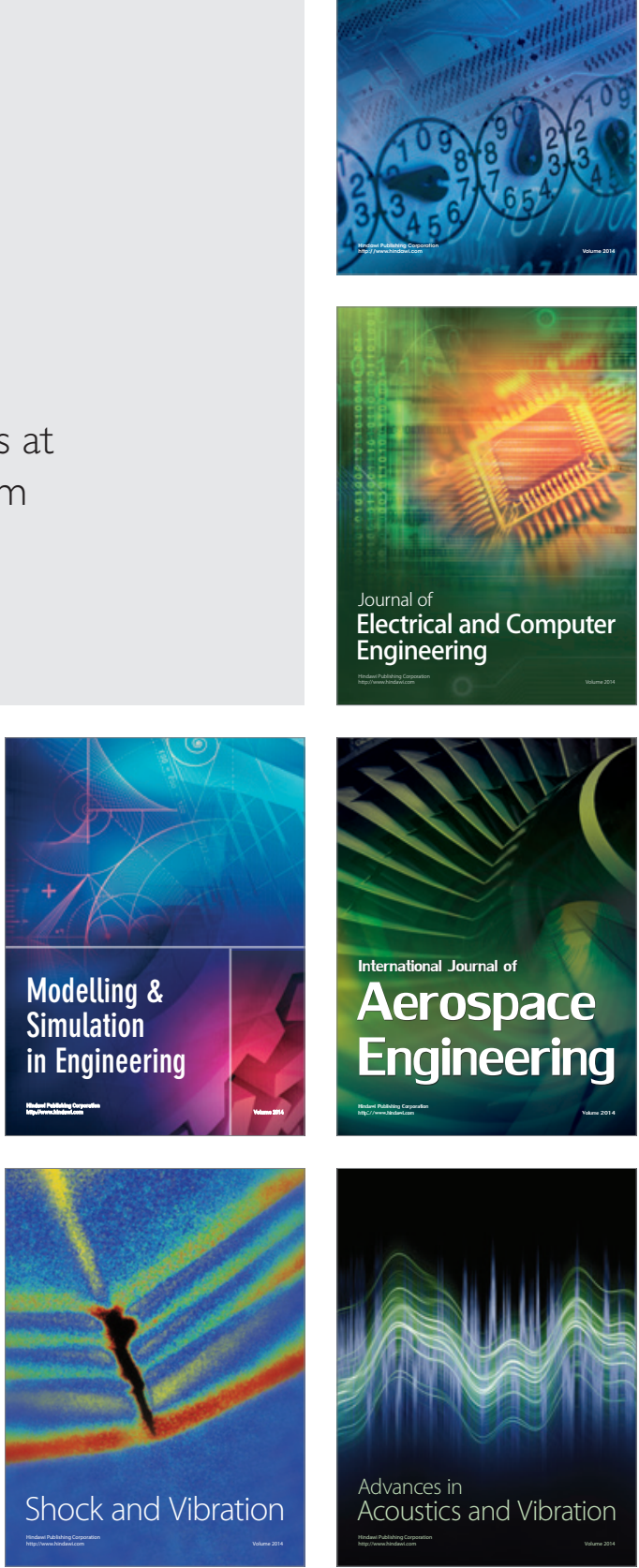